\title{
Outcome of Pregnancies with Fibroids and its Associated Complications: A Prospective Study
}

\author{
Swarna Sudha Pullemalla ${ }^{\circledR 1}$, B. Bhargavi ${ }^{\circledR 2}$ \\ ${ }^{1}$ Assistant Professor, Department of Obstetrics \& Gynaecology, MGMH, Osmania Medical College, Hyderabad, Telangana, India, ${ }^{2}$ Associate Professor, Department of \\ OBG, AIMSR, Chittoor, Andhra Pradesh, India.
}

\section{Abstract}

Background: Fibroids (leiomyomas) are benign smooth muscle cell tumors of the uterus. Although they are extremely common, with an overall incidence of $40 \%$ to $60 \%$ by age 35 and $70 \%$ to $80 \%$ by age 50 , the precise etiology of uterine fibroids remains unclear. Some studies have shown a relationship between uterine fibroids and pregnancy complications, such as preterm birth, premature rupture of membranes (PROM), fetal malpresentation, placental abruption and intrauterine fetal demise. The aim is to study the outcome of pregnancies with fibroids and their associated complications. Materials and methods: The present study was conducted in the Department of Gynecology in a tertiary care hospital. For the study, a total of 40 patients were selected between the age range of 21 to 45 years from the outpatient list of the department of gynecology with pregnancy with fibroid after attending first-trimester ultrasonography examination which diagnosed them. The patients underwent both consequent antenatal care and delivery at the study institute in the study time. Ultrasonogram was done at successive visits to evaluate the change in the size of the fibroid and any associated complications either in fibroid or in pregnancy in general. Results: We observed that 15 patients had threatened miscarriage, 12 had preterm labor, 2 had antepartum bleeding, 3 had abdominal pain needing admission, 2 had laparotomy due to pain, 1 had a postpartum hemorrhage and only one patient needed a blood transfusion. Spontaneous abortion was observed in 2 patients, premature delivery in 15, delivery at 37-41 weeks in 37, vaginal delivery in 5 patients and cesarean section in 44 patients. Conclusion: Within the limitations of the present study, it can be concluded that pregnant women diagnosed with uterine fibroids are at a greater risk of complication during the antepartum, intrapartum, and postpartum periods.

Keywords: Uterine fibroids, pregnancy complications, maternal complications

Corresponding Author: B. Bhargavi, Associate Professor, Department of OBG, AIMSR, Chittoor, Andhra Pradesh, India.

E-mail: drbhargavireddybandi@gmail.com

Received: 25 September 2020

Revised: 18 November 2020

Accepted: 27-11-2020

Published: 30 December 2020

\section{Introduction}

Fibroids (leiomyomas) are benign smooth muscle cell tumors of the uterus. Although they are extremely common, with an overall incidence of $40 \%$ to $60 \%$ by age 35 and $70 \%$ to $80 \%$ by age 50 , the precise etiology of uterine fibroids remains unclear. ${ }^{[1]}$ The diagnosis of fibroids in pregnancy is neither simple nor straightforward. Only $42 \%$ of large fibroids $(>5$ $\mathrm{cm})$ and $12.5 \%$ of smaller fibroids $(3-5 \mathrm{~cm})$ can be diagnosed on physical examination. ${ }^{[2]}$ The ability of ultrasound to detect fibroids in pregnancy is even more limited $(1.4 \%-$ $2.7 \%$ ) primarily due to the difficulty of differentiating fibroids from physiologic thickening of the myometrium. ${ }^{[3]}$ There are conflicting data on the relationship between obstetric outcomes and uterine fibroids, and the mechanism by which fibroids influence obstetric outcomes is unclear. Some studies have shown a relationship between uterine fibroids and preg- nancy complications, such as preterm birth, premature rupture of membranes (PROM), fetal malpresentation, placental abruption and intrauterine fetal demise. ${ }^{[4-6]}$ Hence, the present study was conductedto study the outcome of pregnancies with fibroids and their associated complications.

\section{Subjects and Methods}

The present study was conducted in the Department of Gynecology in a tertiary care hospital from October 2019 to September 2020. The ethical clearance for the study was approved by the ethical committee of the hospital. For the study, a total of 50 patients were selected between the age range of 21 to 45 years from the outpatient list of the department of gynecology with pregnancy with fibroid after attending first-trimester ultrasonography examination which diagnosed them. Informed written consent was obtained from 
the participating patients after verbally explaining to them the protocol of the study. Patients with fibroids of $\geq 2 \mathrm{~cm}$ were included in the study.

\section{Exclusion criteria:}

- History of any surgical manipulation of the uterus such as cesarean section, resection of uterine septum or myomectomy,

- Any uterine malformation,

- Adenomyosis (uterine adenomyoma),

- Any general disease, for example, cerebrovascular, cardiovascular, or diabetes mellitus

- Renal insufficiency.

The patients underwent both consequent antenatal care and delivery at the study institute in the study time. Ultrasonogram was done at successive visits to evaluate the change in the size of the fibroid and any associated complications either in fibroid or in pregnancy in general. The clinical data were tabulated and subjected to statistical analysis.

The statistical analysis of the data was done using SPSS version 11.0 for windows. Chi-square and Student's t-test were used for checking the significance of the data. A p-value of 0.05 and lesser was defined to be statistically significant.

\section{Results}

[Table 1] shows maternal outcomes during the antenatal period. We observed that 15 patients had threatened miscarriage, 12 had preterm labor, 2 had antepartum bleeding, 3 had abdominal pain needing admission, 2 had laparotomy due to pain, 1 had a postpartum hemorrhage and only one patient needed a blood transfusion. [Figure 1] Table 2 shows pregnancy outcomes in participating patients. Spontaneous abortion was observed in 2 patients, premature delivery in 15 , delivery at 37-41 weeks in 37, vaginal delivery in 5 patients and cesarean section in 44 patients. [Figure 2]

\begin{tabular}{|lll|}
\hline \multicolumn{2}{|c|}{ Table 1: Maternal outcome during the antenatal period } \\
\hline Maternal outcome & Number & $\%$ \\
\hline Threatened miscarriage & 15 & 30 \\
\hline Preterm labor & 12 & 24 \\
\hline $\begin{array}{l}\text { Antepartum bleeding } \\
\text { Abdominal pain need- }\end{array}$ & 2 & 4 \\
ing admission & 3 & 6 \\
\hline Laparotomy due to pain & 2 & 4 \\
\hline Postpartum hemorrhage & 1 & 2 \\
\hline Blood transfusion & 1 & 2 \\
\hline
\end{tabular}

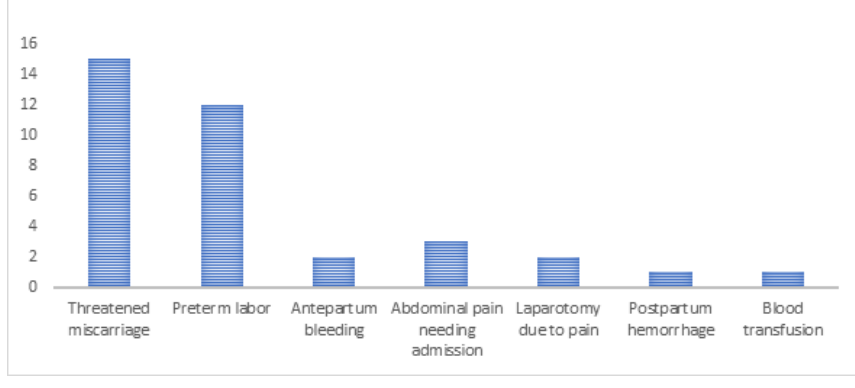

Figure 1: Maternal outcome duringthe antenatal period

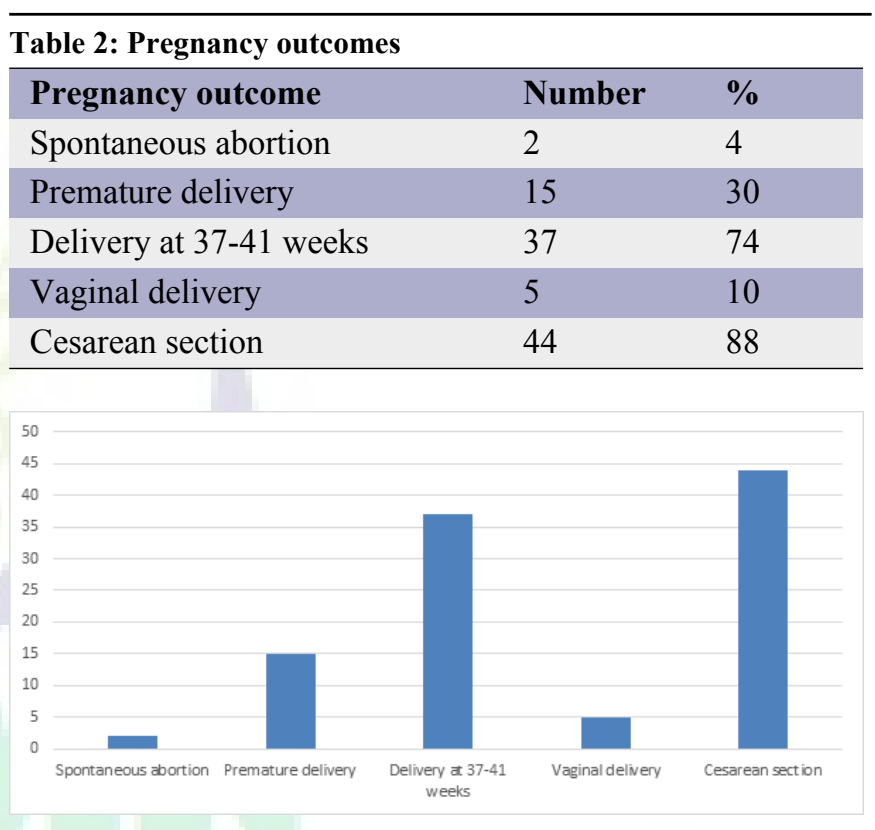

Figure 2: Pregnancy outcomes

\section{Discussion}

In the present study, we observed that Saleh HS et al assessed the obstetric outcome (maternal and fetal) in pregnancy with fibroid. 64 pregnant patients with $>2 \mathrm{~cm}$ fibroid were taken in the study. Maternal age, parity, size of the fibroid, complications during pregnancy, and mode of delivery were noted. The results of obstetric outcomes were spontaneous abortion in $2 \%$, premature delivery in $27.7 \%$, and delivery at $37-41$ weeks of pregnancy in $70.2 \%$. The mode of delivery was vaginal delivery in $15 \%$ and cesarean sections in $85 \%$. Also, 34\% had threatened miscarriage, $21 \%$ had preterm labor, $2 \%$ had antepartum bleeding in the form of placenta previa, $4 \%$ had abdominal pain needing admission, one of them underwent laparotomy and was diagnosed as red degeneration, $2(4 \%)$ had a postpartum hemorrhage, and only one needed 
a blood transfusion. Cesarean sections were done in $85 \%$. Neonatal outcome was acceptable with no perinatal mortality. There was no significant difference between patients with single or multiple fibroids as regards the obstetric outcome or type of fibroid either intramural or subserosal. The obstetric outcome was not significantly affected by the number, size, or type of fibroids. They concluded that fibroids in pregnancy are asymptomatic but may be associated with some complications affecting the course of pregnancy and labor. The results of the study by Saleh HS are comparable to our study. ${ }^{[7]}$ In our study, we observed that 15 patients had threatened miscarriage, 12 had preterm labor, 2 had antepartum bleeding, 3 had abdominal pain needing admission, 2 had laparotomy due to pain, 1 had a postpartum hemorrhage and only one patient needed a blood transfusion. In another study by Zhao $\mathrm{R}$ et al to study the association between uterine fibroids and adverse obstetric outcomes, ${ }^{[8]}$ they conducted a retrospective crosssectional study of 112,403 deliveries from 14 provinces and 39 different hospitals in 2011 in mainland China. They compared pregnancy outcomes in women with and without uterine fibroids who underwent detailed second-trimester obstetric ultrasonography from 18 to 22 weeks. Of 112,403 women who underwent a routine obstetric survey, 3,012 (2.68\%) women were identified with at least 1 fibroid. By univariate and multivariate analyses, the presence of uterine fibroids was significantly associated with cesarean delivery, breech presentation and postpartum hemorrhage. The size of uterine fibroids and location in the uterus had an important effect on the mode of delivery. The findings are consistent with the results of the present study. Thus, pregnant women with uterine fibroids are at increased risk for cesarean delivery, breech presentation and postpartum hemorrhage. Ciavattini A et al studied the impact of sonographically identified multiple or large ( $\geq 5 \mathrm{~cm}$ in diameter) fibroids on obstetric outcomes. ${ }^{[9]}$ The study was performed on 219 women with uterine fibroids. It was reported that compared to women with no fibroids, women with multiple fibroids $(\mathrm{n}=34)$ had a significantly higher rate of preterm birth, cesarean section and breech presentation. Women with large fibroids $(\mathrm{n}=$ 48) had a higher rate of preterm birth and PPROM. Their study indicates that multiple rather than large fibroids are associated with a significantly increased risk of preterm birth and cesarean delivery while large fibroids are associated with a higher risk of PPROM. Egbe TO determined the maternal and foetal outcomes of birth among pregnant women with leiomyoma in two secondary care hospitals in Limbe and Buea, Cameroon. ${ }^{[10]}$ They reported that acute abdominal pain, vaginal bleeding were the clinical presentation of leiomyoma in pregnancy. Cesarean birth, low Apgar score, and postpartum hemorrhage were adverse outcomes recorded, consistent with the results of the present study.

\section{Conclusion}

Within the limitations of the present study, it can be concluded that pregnant women diagnosed with uterine fibroids are at a greater risk of complications during the antepartum, intrapartum, and postpartum periods.

\section{References}

1. Qidwai GI, Caughey AB, Jacoby AF. Obstetric Outcomes in Women With Sonographically Identified Uterine Leiomyomata. Obstet Gynecol. 2006;107(1):376-382. Available from: https://dx.doi.org/10.1097/01.aog.0000196806.25897.7c.

2. Ezzedine DNE. Are Women With Uterine Fibroids at Increased Risk for Adverse Pregnancy Outcome? Clin Obstet Gynecol. 2016;59(1):119-146. Available from: https://doi.org/10.1097/ grf.0000000000000169.

3. Ciavattini A, Clemente N, Carpini GD, Giuseppe JD, Giannubilo SR, Tranquilli AL. Number and size of uterine fibroids and obstetric outcomes. J Matern-Fetal Neo M. 2015;28:484 488. Available from: https://dx.doi.org/10.3109/14767058. 2014.921675

4. Baird DD, Dunson DB, Hill MC, Cousins D, Schectman JM. High cumulative incidence of uterine leiomyoma in black and white women: Ultrasound evidence. Am J Obstet Gynecol. 2003;188(1):100-107. Available from: https://dx.doi.org/10. 1067/mob.2003.99.

5. Muram D, Gillieson M, Walters JH. Myomas of the uterus in pregnancy: Ultrasonographic follow-up. Am J Obstet Gynecol. 1980;138(1):16-19. Available from: https://dx.doi. org/10.1016/0002-9378(80)90005-8.

6. Burton CA, Grimes DA, March CM. Surgical management of leiomyomata during pregnancy. Obstet Gynecol. 1989;74:707709.

7. Saleh HS, Mowafy HE, Hameid AAAE, Sherif HE, Mahfouz EM. Does Uterine Fibroid Adversely Affect Obstetric Outcome of Pregnancy? Biomed Res Int. 2018;2018:1-5. Available from: https://dx.doi.org/10.1155/2018/8367068.

8. Zhao R, Wang X, Zou L, Li G, Chen Y, Li C. Adverse obstetric outcomes in pregnant women with uterine fibroids in China: A multicenter survey involving 112,403 deliveries. PLoS One. 2017;12:0187821. Available from: https://doi.org/ 10.1371/journal.pone.0187821.

9. Ciavattini A, Clemente N, Carpini GD, Giuseppe JD, Giannubilo SR, Tranquilli AL. Number and size of uterine fibroids and obstetric outcomes. J Matern-Fetal Neo M. 2015;28(4):484 488. Available from: https://dx.doi.org/10.3109/14767058. 2014.921675 .

10. Egbe TO, Badjang TG, Tchounzou R, Egbe EN, Ngowe $\mathrm{MN}$. Uterine fibroids in pregnancy: prevalence, clinical presentation, associated factors and outcomes at the Limbe and Buea Regional Hospitals, Cameroon: a cross-sectional study. BMC Res Notes. 2018;11(1):889-889. Available from: https: //dx.doi.org/10.1186/s13104-018-4007-0. 
Copyright: (C) the author(s), 2020. It is an open-access article distributed under the terms of the Creative Commons Attribution License (CC BY 4.0), which permits authors to retain ownership of the copyright for their content, and allow anyone to download, reuse, reprint, modify, distribute and/or copy the content as long as the original authors and source are cited.

How to cite this article: Pullemalla SS, Bhargavi B. Outcome of Pregnancies with Fibroids and its Associated Complications: A Prospective Study. Asian J. Med. Res. 2020;9(4):1-4.

DOI: dx.doi.org/10.47009/ajmr.2020.9.4.OG1

Source of Support: Nil, Conflict of Interest: None declared. 